\title{
Women Having Abortion in Urban Nepal: 2005 and 2010 Compared
}

\author{
Thapa $S,{ }^{1}$ Neupane $S,{ }^{2}$ Basnett I, ${ }^{3}$ Read E ${ }^{4}$
}

${ }^{1}$ Public Health Institute, Washington, DC, USA; Geneva Foundation for Medical Education and Research, Geneva, Switzerland; Patan Academy of Health Sciences, Lalitpur, Nepal

${ }^{2}$ Valley Research Group, Lalitpur, Nepal

${ }^{3}$ Ipas/Nepal, Kathmandu, Nepal

${ }^{4}$ School of Medicine, University of Washington, Seattle, USA

\section{Corresponding Author}

Shyam Thapa

Public Health Institute, 1201 Pennsylvania Ave, Suite 200, Washington, DC, 20004, USA

Email: sthapa22181@gmail.com

\section{Citation}

Thapa S, Neupane S, Basnett I, Read E. Women Having Abortion in Urban Nepal: 2005 and 2010 Compared. Kathmandu Univ Med J 2012;39(3):813.

\section{ABSTRACT \\ Background}

The use of abortion services at the Maternity Hospital clinic, the largest public sector abortion clinic in Nepal, has risen over the years. Whether the profile of the clients, reasons for abortion, and contraceptive use have changed are not known and need to be investigated.

\section{Objectives}

This paper evaluates changes between 2005 and 2010 in the socio-demographic profile of abortion users, reasons for seeking abortion, and contraceptive use of two cohorts of women who had first-trimester abortion at the Maternity Hospital.

\section{Methods}

We used data from two similar surveys conducted in 2005 and 2010 among 672 and 392 women, respectively, who obtained first-trimester surgical abortion in a large public sector clinic. We analyzed trend data in service utilization and carried out a cost analysis.

\section{Results}

The number of women having abortions has steadily increased over the years, and cumulatively about 19,800 women have received services. The profile of the clients at this clinic has remained essentially the same between 2005 and 2010. The typical users of abortion services at the clinic were 27 years old with two living children, mostly married, with the majority not wanting to have more children. About half of them used a contraceptive method-mostly condoms, withdrawal, the pill and rhythm-in the month of unintended pregnancy, suggesting failures with these methods. Health concerns, dislike of available methods, and perceived low risk of pregnancy were common reasons for not using a contraceptive method.

\section{Conclusion}

Despite increases in the number of clients, the socio-demographic profile of the abortion clients has remained similar over the years. The linkage between the abortion and family planning clinics needs to be strengthened.

\section{KEY WORDS}

Abortion, client characteristics, family planning, Nepal

\section{INTRODUCTION}

Understanding how a clinic is providing its services, who is accessing the services, how the services have been perceived by the clients, and whether the clients' profile has changed over time are some of the basic questions that pertain to strengthening health service delivery and meeting the clients' needs. This paper compares the profile of abortion clients, whether reasons for abortion have changed, and whether contraceptive use has changed between two time periods at a large public sector clinic in Nepal. 
Nepal's first service for safe induced abortion (surgical evacuation) was established in 2004 at the Paropakar Maternity and Women's Hospital (Maternity Hospital) in the capital city Kathmandu. Since then abortion services have been expanded through many public, non-governmental and private clinics. By mid-2011, nearly 500,000 women had obtained abortion services from 487 Ministry of Health-certified abortion clinics in the three sectors. A total of 1,276 doctors and nurses have been trained in safe abortion services. ${ }^{1}$

In 2005, a study was conducted among women at the Maternity Hospital abortion clinic to examine the clients' profile, the context of demand for services, affordability, and satisfaction with services. ${ }^{2}$ One of the findings of the study was that those who sought and obtained services were overwhelmingly married women, most of whom wanted to stop having children. Further, the basic profile of the women seeking abortion services was essentially similar to what had been found in previous research. ${ }^{3}$ In 2010, another survey was conducted in the same clinic using essentially the same survey instrument. This afforded the opportunity to assess any changes over the years which might have occurred in the demographic and socioeconomic composition of the clients accessing abortion services.

We first provide a review of the trend in the utilization of abortion services and a cost analysis for the period 2004-2009. Following this, we present key findings based on the two surveys conducted five years apart. The basic research questions that we sought to examine are: With the continued availability of services, were there significant changes in the composition of the abortion clients during the five-year period? Has the primary reason for seeking abortion changed over time? Has contraceptive use, the proximate determinant of unintended pregnancy, changed over time? And, finally, what implications might these findings have on strengthening service delivery?

\section{METHODS}

Data from two rounds of cross-sectional surveys among women who obtained services at the Maternity Hospital abortion clinic were analyzed. Neither of the studies involved testing a new approach or modifying the existing quality or standard of services. Rather, the studies were designed to get a "snap shot" of the standards of care and services as they existed.

The surveys included the full spectrum of service users without limiting the sample to fit a particular set of inclusion criteria. The eligible respondents for both surveys were, hence, defined to be those who presented themselves at the clinics for surgical abortion (evacuation) within the first 12 weeks of pregnancy and received treatment. The procedure Manual Vacuum Aspiration (MVA) was used for surgical abortion. The procedure was performed by administering paracervical block (local anaesthesia) and was done on an outpatient basis. As part of the standards of care, each client also received counselling on contraceptives. For those wanting to use a method, IUDs, injectables, condoms and the pill were provided at discharge at the same clinic; sterilization services were also offered and provided through a separate family planning clinic located in the same hospital complex.

The 2005 survey was implemented over two months-1 June through 31 July 2005 . The 2010 survey was conducted, 20 December 2009 through 26 February 2010, and because most of the interviews took place in the first two months in 2010 , this is referred to as the 2010 survey.

The sample size for both the surveys was predetermined. All women who sought surgical evacuation and were eligible for the services during the study period were contacted. In the 2005 and 2010 surveys, a total of 680 and 398 women were contacted, respectively. Of them, 672 and 392, respectively, consented to participate in the surveys. These two survey samples represented two cohorts of women.

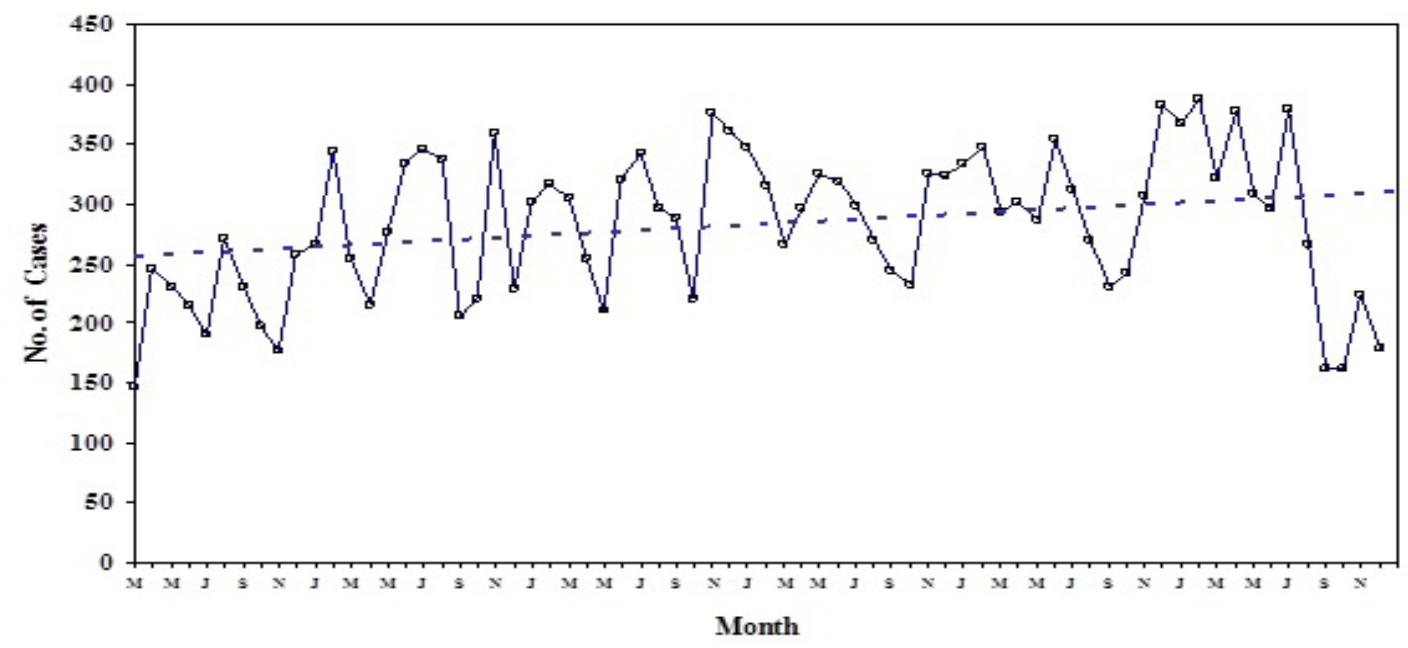

Figure 1. Monthly number of induced abortions performed at the Maternity Hospital, March 2004-December 2009.

Note: The first month labeled " $\mathrm{M}$ " refers to March 2004. The trend (dotted) line is based on a linear regression. The cumulative number of cases is 19,798 . 
All the interviewers were females who were trained in the contents and the techniques of interviewing with sensitivity to clients seeking abortion counseling and services. Several of the questions in the surveys were partially or fully openended with coded responses. A written informed consent was read to each potential respondent, and a verbal consent from each was sought before the interview. Both of the study protocols were approved by the Nepal Health Research Council.

Because the two surveys had different sample sizes, it was not possible to merge the data to perform any statistical tests on the survey responses. Further, the 2005 individual-level data set was no longer available for estimating confidence intervals for strict statistical comparison. For these reasons, we arbitrarily chose at least four percentage points difference in the results (referring to percent distribution) between the samples to represent real differences. Our rationale for this choice was that these differences would have more relevance and significance from a service delivery perspective than would the statistical significance alone.

\section{RESULTS}

\section{Trends in Service Utilization}

Figure 1 shows the monthly number of induced abortions performed at the Maternity Hospital $(\mathrm{MH})$ clinic between the inception of the service in 2004 and the end of 2009. The client volume fluctuated as client numbers were lower in the autumn (festival season) and higher in the winter months.

Despite the fluctuations, the overall trend (as shown by the dotted line) has been one of steady, though modest, increase over time. Between March 2004 and the end of 2009, nearly 19,800 women obtained services from the clinic. In 2005, the number of clients averaged 282 per month; by 2009 it had increased to 386 per month.

\section{Cost Analysis}

Table 1 shows results of a cost analysis of abortion services at the clinic between March 2004 and December 2009. The cost includes both the start-up (fixed) cost, which was discounted over 10 years, and the operational (variable) cost.

The total cost per user incurred by the clinic was Rs. 971 (US\$13.2) in 2004 and declined to Rs. 796 (\$10.26) in 2009. This largely reflected the increase in the number of clients over time. The user fee for services was Rs. 900 in 2004 and 2005 and Rs. 1,000 for the years 2006 through 2009. The revenue from the user fees offset the clinic's expenditures on the services every year except for the initial year.

\section{Clients' Profile}

The median ages of the 2005 and 2010 cohorts were 26 and 27 , respectively. The age group 25-29 comprised the highest percentage of women using the services in both periods (table 2). A little over one-quarter (28\% v. $29 \%$ ) of the clients were illiterate and about one in five $(18 \%$ v. $19 \%)$ had college or higher educational attainment. The overwhelming majorities $(97 \%)$ of the clients were married; $2 \%$ and $2.5 \%$ were single; and less than $1.0 \%$ were divorced.

Of the total, $12 \%$ v. $13 \%$ of the women had never had a live birth (table 3). Among those who had a live birth, the average number of living children was about two for both cohorts of women. The most common sex composition of living children was one son and one daughter (26\% v. 29\%) followed by one son ( $20 \%$ in both groups). Among the 2005 and 2010 clients, the percentages that intended to have a / another child sometime in the future were $29 \%$ and $32 \%$, respectively. More of the 2005 than the 2010 cohort were uncertain about having another child in the future (14\% v. $5 \%$ ). The majority of women in both groups (57\% and $63 \%$ ) did not wish to have any more children.

In response to an open-ended question regarding the context (circumstances) that resulted in an unintended pregnancy (table 4), 41\% of those in the 2005 cohort responded that the contraceptive or non-program methods (e.g., withdrawal or rhythm) failed. About $35 \%$ said they had unprotected sex because they did not think they could become pregnant. Just over one quarter (27\%) said they took a chance even when they thought they might become pregnant. Among the 2010 cohort, each of the threetaking a chance, thinking that there was a low probability of becoming pregnant, and having a contraceptive failwere important reasons for about an equal proportion of women (31\% and 33\%).

As shown in table 5, peri-contraceptive use was higher among the 2005 than the 2010 cohort (62\% v. 53\%). Among those who had used a method, the most common was condom (38\% and $29 \%$ ) followed by withdrawal (used by $25 \%$ and $27 \%$ ). About one in five were using the pill in both groups. Women who were not using a method to prevent an unintended pregnancy were asked an openended question about the main reason for not doing so. Because the codes were not the same for the 2005 and 2010 surveys, comparisons were not meaningful. Among the women interviewed in the 2010 survey, the multiple reasons given in rank order were (data not shown in a table): actual or perceived health risk (47\%), perceived low risk of pregnancy $(18 \%)$, dislike (either by self or the partner) of the available methods (18\%), and forgot to use the method or method not readily available (13\%). Injectable was the most common method used at discharge (60\% among the 2005 cohort and $30 \%$ by the 2010 cohort) (table 5). Among the former, the IUD was the second most common method, whereas among the latter cohort, condoms and the pill were common methods ( $20 \%$ and $22 \%$ ). About one fourth (22\%) of the 2010 cohort of women left the clinic without any method, while $2 \%$ of the 2005 cohort did so. 
Table 1. Cost analysis (in Nepali Rupees) of the surgical abortion services at the Maternity Hospital, 2004-2009.

\begin{tabular}{|c|c|c|c|c|c|c|}
\hline Year & 2004* & 2005 & 2006 & 2007 & 2008 & 2009 \\
\hline Total number of service users & 2,163 & 3,387 & 3,593 & 3,565 & 3,660 & 3,430 \\
\hline $\begin{array}{l}\text { Service user charge / fee } \\
\text { Clinic cost of providing services (per client) }\end{array}$ & 900 & 900 & 1,000 & 1,000 & 1,000 & 1,000 \\
\hline A. Variable cost & 786.3 & 661.0 & 637.4 & 640.5 & 630.3 & 655.8 \\
\hline B. Fixed cost & 184.9 & 141.7 & 133.6 & 134.6 & 131.2 & 139.9 \\
\hline C. Total cost $(A+B)$ & 971.2 & 802.7 & 771.0 & 775.1 & 761.5 & 795.8 \\
\hline Total expenditure of clinic & $2,100,750$ & $2,718,750$ & $2,770,250$ & $2,763,250$ & $2,787,000$ & $2,729,500$ \\
\hline Total revenue (from service user fees) & $1,946,700$ & $3,048,300$ & $3,593,000$ & $3,565,000$ & $3,660,000$ & $3,430,000$ \\
\hline Net balance (revenue-expenditure) & $-154,050$ & 329,550 & 822,750 & 801,750 & 873,000 & 700,500 \\
\hline Average exchange rate (US\$) & 73.53 & 71.37 & 72.83 & 66.80 & 69.14 & 77.57 \\
\hline
\end{tabular}

*Beginning in March

Table 2. Demographic and socioeconomic characteristics of the women who had abortions at the Maternity Hospital, 2005 and 2010.

\begin{tabular}{|c|c|c|c|c|}
\hline \multirow[t]{2}{*}{ Variable } & \multicolumn{3}{|c|}{2005} & 2010 \\
\hline & $\%$ & $\mathbf{N}$ & $\%$ & $\mathbf{N}$ \\
\hline \multicolumn{5}{|l|}{ Age group } \\
\hline $16-19$ & 5.8 & 39 & 7.4 & 29 \\
\hline $20-24$ & 29.9 & 201 & 25.8 & 101 \\
\hline $25-29$ & 34.4 & 231 & 30.9 & 121 \\
\hline $30-34$ & 19.2 & 129 & 22.2 & 87 \\
\hline $35-39$ & 10.7 & 72 & 10.5 & 41 \\
\hline $40-48$ & 5.8 & 39 & 3.3 & 13 \\
\hline Total & 100.0 & 672 & 100.0 & 392 \\
\hline Mean & $26.9 \pm 5.5$ & 672 & $27.5 \pm 5.8$ & 392 \\
\hline Median & 26.0 & 672 & 27.0 & 392 \\
\hline \multicolumn{5}{|l|}{ Education } \\
\hline Illiterate & 28.4 & 191 & 28.8 & 113 \\
\hline Primary (grades 1-5) & 9.8 & 66 & 11.7 & 46 \\
\hline Secondary (grades 6-12) & 43.9 & 295 & 40.8 & 160 \\
\hline College or higher & 17.9 & 120 & 18.6 & 73 \\
\hline Total & 100.0 & 672 & 100.0 & 392 \\
\hline \multicolumn{5}{|l|}{ Marital status } \\
\hline Unmarried and not engaged & 1.8 & 12 & 1.0 & 4 \\
\hline Unmarried but engaged & 0.7 & 5 & 1.0 & 4 \\
\hline Married & 96.7 & 650 & 97.4 & 382 \\
\hline $\begin{array}{l}\text { Divorced / separated / wid- } \\
\text { owed }\end{array}$ & 0.7 & 5 & 0.5 & 2 \\
\hline Total & 100.0 & 672 & 100.0 & 392 \\
\hline
\end{tabular}

\section{DISCUSSION}

The abortion clinic at the Maternity Hospital marked its five-year anniversary of uninterrupted services in March 2010. The data from this particular clinic are important not only because this is where the services began but also because it has been the lead public sector clinic with the highest number of clients among all the abortion clinics in the country and continues to serve as a referral clinic. The
Table 3. Parity and fertility preference of women who had abortions at the Maternity Hospital, 2005 and 2010.

\begin{tabular}{|c|c|c|c|c|}
\hline \multirow[t]{2}{*}{ Variable } & \multicolumn{2}{|l|}{2005} & \multicolumn{2}{|l|}{2010} \\
\hline & $\%$ & $\mathbf{N}$ & $\%$ & $\mathbf{N}$ \\
\hline \multicolumn{5}{|l|}{ Ever had a child } \\
\hline Yes & 88.1 & 592 & 87.2 & 342 \\
\hline No & 11.9 & 80 & 12.8 & 50 \\
\hline Total & 100.0 & 672 & 100.0 & 392 \\
\hline $\begin{array}{l}\text { Average no. of living children } \\
\text { (among those who had a } \\
\text { child before) }\end{array}$ & $1.97 \pm 1.03$ & 592 & $(1.97 \pm 1.07)$ & 342 \\
\hline \multicolumn{5}{|l|}{ No. of living children by sex } \\
\hline One son, one daughter & 26.0 & 154 & 28.7 & 98 \\
\hline One son & 19.9 & 115 & 19.9 & 68 \\
\hline One daughter & 14.9 & 88 & 14.0 & 48 \\
\hline Two sons & 13.1 & 78 & 13.2 & 45 \\
\hline Two daughters & 4.7 & 28 & 4.7 & 16 \\
\hline Two daughters, one son & 5.2 & 31 & 5.6 & 19 \\
\hline Two sons, one daughter & 5.2 & 31 & 4.1 & 14 \\
\hline All other & 11.3 & 67 & 9.9 & 34 \\
\hline Total & 100.0 & 592 & 100.0 & 342 \\
\hline \multicolumn{5}{|c|}{ Intention to have a / another child in the future } \\
\hline Yes & 28.9 & 194 & 32.1 & 126 \\
\hline No & 57.4 & 386 & 62.5 & 245 \\
\hline Not sure & 13.7 & 92 & 5.4 & 21 \\
\hline Total & 100.0 & 672 & 100.0 & 392 \\
\hline
\end{tabular}

clients in this particular clinic can, therefore, be expected to be more representative than those using other public sector clinics. The data from the 2005 survey serve as a baseline for assessing changes over time and evaluating how the composition of clients may have changed from the early adopters (vanguard users) of services.

Evidence from both surveys supports the previous finding from Nepal that most abortions are sought and received by married women and the primary reason for abortion is having already achieved their desired family size. ${ }^{3}$ This reason has not changed much over time, at least among the women who attended the $\mathrm{MH}$ clinic. The proportion of 
Table 4. Context resulting in unintended pregnancy among women who had abortions at the Maternity Hospital, 2005 and 2010.

\begin{tabular}{lrrrrr} 
& 2005 & & 2010 \\
Variable & $\%$ & N & $\%$ & N \\
Context & & & & \\
\hline Took a chance & 27.4 & 184 & 33.2 & 130 \\
\hline Contraception / method failed & 40.9 & 275 & 32.7 & 128 \\
\hline Did not think I would be pregnant & 35.1 & 236 & 30.9 & 121 \\
\hline Did not plan to have intercourse at all & 4.5 & 30 & 3.3 & 13 \\
\hline Other & 1.0 & 7 & na & 0 \\
\hline Total & 100.0 & 672 & 100.0 & 392
\end{tabular}

The 2005 survey included 60 cases with multiple response.

Table 5. Peri-contraceptive use among women who had abortions at the Maternity Hospital, 2005 and 2010.

\begin{tabular}{|c|c|c|c|c|}
\hline \multirow[t]{2}{*}{ Variable } & \multirow{2}{*}{$\begin{array}{r}2005 \\
\%\end{array}$} & \multicolumn{3}{|c|}{2010} \\
\hline & & $\mathbf{N}$ & $\%$ & $\mathbf{N}$ \\
\hline \multicolumn{5}{|c|}{ Peri-contraceptive use } \\
\hline Yes & 61.5 & 413 & 52.8 & 207 \\
\hline No & 38.5 & 259 & 47.2 & 185 \\
\hline Total & 100.0 & 672 & 100.0 & 392 \\
\hline \multicolumn{5}{|c|}{ Among women who used a method, method used } \\
\hline Condom & 38.3 & 158 & 29.0 & 60 \\
\hline Withdrawal & 24.5 & 101 & 27.1 & 56 \\
\hline Pills & 18.2 & 75 & 19.3 & 40 \\
\hline Rhythm & 10.7 & 44 & 15.9 & 33 \\
\hline Injectables & 6.3 & 26 & 6.8 & 14 \\
\hline Norplant & 0.2 & 1 & na & 0 \\
\hline IUD (Copper T) & 0.5 & 2 & na & 0 \\
\hline Vasectomy & 1.2 & 5 & 1.4 & 3 \\
\hline Minilap & 0.2 & 1 & 0.5 & 1 \\
\hline Total & 100.0 & 413 & 100.0 & 207 \\
\hline \multicolumn{5}{|c|}{ Contraceptive method dispensed at discharge } \\
\hline Condom & 4.0 & 27 & 20.2 & 79 \\
\hline Pills & 7.4 & 50 & 22.4 & 88 \\
\hline Injectables & 60.3 & 405 & 29.8 & 117 \\
\hline IUD & 26.2 & 176 & na & 0 \\
\hline Other & na & 0 & 5.9 & 23 \\
\hline None & 2.1 & 14 & 21.7 & 85 \\
\hline Total & 100.0 & 672 & 100.0 & 392 \\
\hline
\end{tabular}

na=not applicable

clients wanting no more children may have increased over time. That would also be consistent with rapidly declining fertility preferences and actual fertility in both urban and rural Nepal over the years. ${ }^{4}$ A related analysis based on the 2010 survey found that the basic profile of the $\mathrm{MH}$ abortion clinic clients was similar to that of a large non-government (NGO) abortion clinic. ${ }^{5}$ These data suggest not only that the clients' profile has essentially remained the same over time, but that the profiles are similar for the public and NGO sector clinics, at least in the capital city. The findings can be used for estimating potential demand for services, planning, and training service providers.

A significant proportion of the abortion clients in both time periods reported using contraception in the month of unintended pregnancy. Part of the reason for higher use among the 2005 cohort could have been due to the fact that women who were breastfeeding their children under six months of age were counted as using lactationalamenorrhea method. This difference notwithstanding, among clients in both cohorts, the four most commonly used peri-contraceptives, particularly the non-program methods-withdrawal and abstinence-are known to have higher real-life failure rates than other methods due to a combination of poor compliance and method failure. ${ }^{6}$ For some of these women, abortion may have been the only choice; but for many, abortion could have been avoided by effective contraceptive use. In this context, a critical look at the family planning program's methods of communication and counseling could be highly useful. It needs to be emphasized that the availability of and access to abortion has changed the landscape in which reproductive decisions are made and services are accessed among the women (and men) in Nepal.

Although the clients in both time periods were similar in their background characteristics and the contraceptive methods most commonly used by them prior to the abortion remained the same, it was clear from the data that contraceptive methods dispensed to the clients (at the time of discharge) varied vastly in the two time periods. In 2005 injectables and IUDs were the two predominant methods at discharge. However, in 2010 while injectables remained the most popular method at discharge they were used by only half as many women and pills were the second most common method. To the extent that this finding is an indicator of the contraceptive supply and provision situation in the clinic, these data suggest the need to review the family planning program in the clinic and hospital at large. The supply of IUDs and implants has been erratic. Further, the comprehensive family planning services are provided in a clinic that is separate from the abortion clinic. Although the two clinics are within the same hospital complex an effective referral system is not in place.

There continues to be a lack of effective linkages between the two clinics, although some efforts have been initiated in recent times. In the existing service delivery system, when an abortion client is referred to the family planning clinic, it is not feasible to keep track of the outcome nor is there any way to assign a priority to the abortion clients. Consequently, the contraceptive needs of many of the abortion clients may remain unaddressed and therefore go unmet. A comprehensive review of the policy, management, and service delivery issues aimed at identifying better and more effective referral and integration is urgently needed. Because this clinic is the lead among all clinics in the public sector, what happens or does not happen in this particular 
clinic has ramifications for other clinics as well. In this sense, it is all the more important to develop a model of service delivery that can be emulated in other similar clinics.

\section{CONCLUSION}

The demand for abortion services at the Maternity Hospital clinic has risen over the years. The clinic has achieved a positive cash flow in recent years, and in 2009 the cost of providing the services was Rs. 796 (\$10.26) per client. The profile of the clients at this clinic has remained essentially the same between those accessing services in 2005 and in 2010. The typical users of abortion services at the clinic are around 27 years old with two living children, most are married, with the majority not wanting to have more children. About half of them have used a contraceptive method-mostly condoms, withdrawal, the pill and rhythm method-during the month of unintended pregnancy, suggesting failures with these methods. Health concerns-

\section{REFERENCES}

1. Sharma S. Personal communication. Kathmandu: Ipas/Nepal; March 2012.

2. Thapa S, Malla K, Basnett I. Safe abortion services in Nepal: Initial years of availability and utilization. A study report. Kathmandu, Nepal: Ipas/Nepal; 2007.

3. Thapa S, Padhye S. Induced abortion in urban Nepal. International Family Planning Perspectives 2001;27:144-147. perceived or actual-dislike of available methods and perceived low risk of pregnancy are frequently cited reasons for not using a contraceptive method. Although abortion is probably unavoidable for some women, family planning programs could play a more effective role in preventing unintended pregnancies. The linkage between the abortion and family planning clinics needs to be strengthened.

\section{ACKNOWLEDGEMENT}

Ipas/Nepal provided support, through Valley Research Group, for both the 2005 and 2010 surveys. The authors thank Dr. Kasturi Malla and Dr. Lata Bajracharya, former directors, Maternity Hospital, for facilitating the implementation of the two surveys; Shital Bhadari for his assistance in sampling; Jaya Poudel for on-site oversight; and the 2005 and 2010 survey supervisors and interviewers. The authors are, however, fully responsible for the contents of the paper and interpretation of the data.

4. Macro International Inc. Trends in Demographic and Reproductive Health Indicators in Nepal. Calverton, Maryland, USA: Macro International Inc.; 2007.

5. Thapa S, Neupane S, Read E. A comparison of clients having abortion in public and non-government clinics in urban Nepal.

6. World Health Organization Department of Reproductive Health and Research (WHO/RHR) and Johns Hopkins Bloomberg School of Public Health/Center for Communication Programs (CCP), INFO Project. Family Planning: A Global Handbook for Providers. Baltimore and Geneva: CCP and WHO; 2007. 